\title{
Hydrogen-Bond and Solvent Dynamics in Transition Metal Complexes: A Combined Simulation and NMR-Investigation
}

\author{
Jing Huang, ${ }^{\dagger}$ Daniel Häussinger, ${ }^{\dagger}$ Urs Gellrich, ${ }^{\ddagger}$ Wolfgang Seiche, ${ }^{\ddagger}$ Bernhard Breit, ${ }^{\ddagger}$ \\ and Markus Meuwly*,†
}

\author{
${ }^{\dagger}$ Department of Chemistry, University of Basel, Klingelbergstrasse 80, 4056 Basel, Switzerland, and \\ ${ }^{*}$ Institute für Organische Chemie und Biochemie, Albert-Ludwigs-Unversität, Freiburg, Germany
}

\section{Supporting Information}

\begin{abstract}
Self-assembling ligands through complementary hydrogen-bonding in the coordination sphere of a transition metal provides catalysts with unique properties for carboncarbon and carbon-heteroatom formation. Their most distinguishing chemical bonding pattern is a double-hydrogen-bonded motif, which determines much of the chemical functionality. Here, we discuss the possibility of double proton transfer (DPT) along this motif using computational and experimental methods. The infrared and NMR spectral signatures for the double-hydrogen-bonded motif are analyzed. Atomistic simulations and experiments suggest that the dynamics of the catalyst is surprisingly complex and displays at least three different dynamical regimes which can be distinguished with NMR spectroscopy and analyzed from computation. The two hydrogen bonds are kept intact and in rapid tautomeric exchange down to $125 \mathrm{~K}$, which provides an estimate of $5 \mathrm{kcal} / \mathrm{mol}$ for the barrier for DPT. This is confirmed by the simulations which predict $5.8 \mathrm{kcal} / \mathrm{mol}$ for double proton transfer. A mechanistic interpretation is provided and the distribution of the solvent shell surrounding the catalyst is characterized from extensive simulations.
\end{abstract}

\section{INTRODUCTION}

During chemical transformations, and catalytic reactions in particular, conformations and reactivities of the chemical species involved can often not be directly observed and characterized. In other words, the majority of information concerning the chemical step is often inferred from an interpolation between the end points, i.e., educts and products, which are the thermodynamically stable compounds. This is a major drawback if detailed information concerning the actual reactive step(s) is sought. Better understanding of the intermediates would, for example, provide useful and much-needed knowledge concerning potential optimization strategies of chemical compounds. Under such circumstances, complementary techniques, including various spectroscopies and computational investigations can give valuable insights.

Over the past 10 years, computational techniques to study catalysts have matured considerably. ${ }^{1}$ Examples for successful investigations include the Hajos-Parrish reaction, ${ }^{2}$ anti-Mannich reactions, ${ }^{3}$ or insights into amine binding to Palladiumcomplexes. ${ }^{4}$ As many important catalytic reactions are carried out in solution, the activity and chemical selectivity of the catalyst can be modulated by additional factors beyond purely energetic ones: the solvent environment, the inter- and intramolecular dynamics and the conformations involved. Although much progress has been made in electronic structure methodsparticularly at the density functional theory (DFT) level-such methods are not particularly useful to investigate the structure and dynamics of solvated transition-metal complexes over sufficiently long time scales (nanoseconds). In the present work, we present an alternative approach based on molecular dynamics (MD) simulations and elaborate force fields and validate them with temperature-dependent NMR studies. To follow the nuclear dynamics on chemically relevant time scales (multiple nanoseconds to milliseconds), molecular dynamics (MD) simulations and NMR spectroscopy are ideal methods. For such long time scales, electronic structure methods cannot be applied. To this end, force field-based methods capable of handling metal-containing compounds and reactivity involving hydrogen/proton transfer are combined. This is possible with VALBOND-TRANS (suitable for transition metal complexes ${ }^{5-7}$ ) and molecular mechanics with proton transfer (MMPT). ${ }^{8}$ As was pointed out recently, molecular-mechanics-based methods can provide the same, or even better accuracy compared to some DFT calculations, if a suitably parametrized force field is available. ${ }^{9}$

The performance of a transition metal catalyst can be tuned efficiently by employing appropriate donor ligands which bind to the metal center and thus craft the microenvironment. One particularly interesting class is bidentate ligands with a covalent connection of the two donor sites which allow one to more efficiently control the chemical selectivity because of the reduced degrees of freedom leading to a smaller number of competing transition states. Examples include Ruthenium/BINAP ${ }^{10}$ and Rhodium/XANTPHOS ${ }^{11}$ catalysts. While these bidentate ligands provide unique selectivity in homogeneous catalysis, the synthesis of these ligands can be troublesome, time-consuming, and

Received: September 21, 2012

Published: November 5, 2012 
expensive. An alternative to bidentate ligands with a covalent bond between the two donor sites was proposed as a new concept through generating bidentate ligands by self-assembly of monodentate ligands via complementary hydrogen bonding. ${ }^{12-14}$

Self-assembling ligands through complementary hydrogenbonding in the coordination sphere of a transition metal has provided catalysts with unique properties for carbon-carbon and carbon-heteroatom formation. Their most distinguishing chemical bonding pattern is a double-hydrogen-bonded motif which determines much of the chemical functionality. A typical example is the self-assembly of 6-diphenylhposphanylpyridone (6-DPPon) in the presence of a transition metal such as platinum(II) and rhodium(I). Such a complex can provide high activity and regioselectivity in the hydroformylation of a range of functionalized terminal alkenes. ${ }^{12}$ The approach is intrinsically combinatorial and thus self-assembled ligand libraries have been prepared and tested in various catalytic transformations. ${ }^{15}$

A distinguishing motif of the ligands is their hydrogen-bonding pattern, which consists of a double-hydrogen bond and leads to increased conformational flexibility. Previously, the cis- $\left[\mathrm{Cl}_{2} \mathrm{Pt}\right.$ (6-DPPon $)_{2}$ ] complex has been characterized in detail using a range of spectroscopic methods (UV-vis, IR, NMR, X-ray) and DFT calculations were used to rationalize a number of observations. ${ }^{16}$ However, due to the noncovalent $\mathrm{H}$-bonded motif, the complex is rather dynamical in particular around the double-hydrogenbond. Alternatively, the covalent bonds between the Pt-center induce strain into the molecular architecture and will affect the dynamics along the double proton transfer motif. Furthermore, solvent effects are expected to play an important role and methods beyond electronic structure calculations are needed. The present work is a first attempt to link the time scales amenable to different computational and experimental techniques to characterize the fundamental mode-of-action of a solvated transition metal catalyst. The methods employed here are suitable to follow the inter- and intramolecular dynamics on sufficiently long time scales and allow to bridge the gap between the time scales relevant to the chemical process (sub- $\mu \mathrm{s}$ to $\mathrm{s}$ ) and those amenable to computation (several hundred nanoseconds). From such a combined computational/experimental approach, additional, functionally relevant insights can be gained which should assist in an improved understanding of the mode-ofaction for a given catalyst and should assist catalyst-optimization in the future. Particularly exciting areas include optimization of existing catalysts, catalyst design beyond the first coordination sphere, the influence of coordinating solvents, and finally the dynamics during the reactive $\operatorname{step}(\mathrm{s})$.

\section{METHODS}

Intermolecular Interactions. As illustrated in Figure 1, the $\left[\mathrm{Cl}_{2} \mathrm{Pt}(6-\mathrm{DPPon})_{2}\right]$ complex is partitioned into three parts that are treated with different force fields: the coordination sphere with VALBOND, ${ }^{7}$ the hydrogen bonding motifs with $\mathrm{MMPT}^{8}{ }^{8}$ and the remaining atoms with standard CHARMM force field. ${ }^{17}$

The coordination sphere contains the center Pt atom and the ligand atoms $\mathrm{P}$ and $\mathrm{Cl}$. These five atoms are treated with VALBOND, which replaces the harmonic angle bending potential in conventional force field with more sophisticated functional forms to capture bending energies over a wide range of angular distortions. ${ }^{5,6,18}$ VALBOND is also applicable to hypervalent compounds by means of a 3-center-4-electron bonding model. It should be pointed out that VALBOND uses a 12-electron rule so all transition metals are considered hypervalent. $^{6,19,20}$ Thus VALBOND can describe various
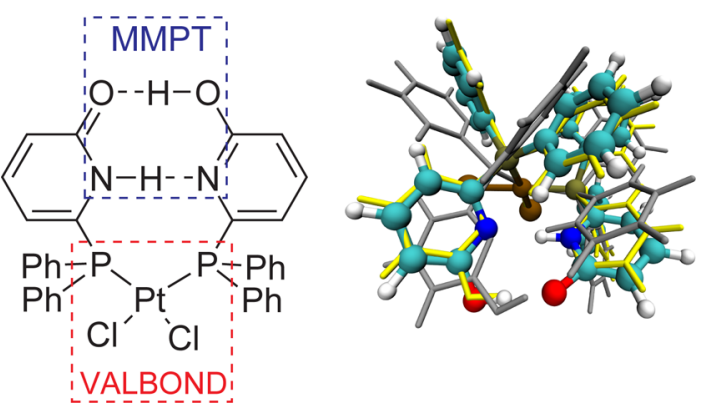

Figure 1. cis- $\left[\mathrm{Cl}_{2} \mathrm{Pt}(6-\mathrm{DPP} \text { ) })_{2}\right]$. Left panel: the complex is partitioned into three parts treated with different force fields: the coordination sphere with VALBOND, the hydrogen bonding motifs with MMPT, and the remaining atoms with standard CHARMM force field. Right panel: Equilibrium structures of $c i s-\left[\mathrm{Cl}_{2} \mathrm{Pt}(6-\mathrm{DPP} \text { on })_{2}\right]$ deduced from optimization with force field (ball and stick), X-ray crystallography (yellow licorice) and DFT optimization (silver licorice), respectively.

geometries found in transition metal complexes, such as octahedral, trigonal bipyramidal, and square planar. For more detailed explanation and formula of nonhypervalent and hypervalent VALBOND, the reader is referred to the original literature.

The atoms involved in the hydrogen bonding between the pyridone (PY) and hydroxypyridine (HPY) rings are treated with MMPT, a reactive force field for proton dynamics. ${ }^{8}$ Briefly, MMPT uses parametrized three-dimensional potential energy surfaces (PESs) $V(R, \rho, \theta)$ to describe the interactions within a general $\mathrm{DH}-\mathrm{A}$ motif where $\mathrm{D}$ is the donor, $\mathrm{H}$ is the hydrogen, and $\mathrm{A}$ is the acceptor atom. $R$ is the distance between donor and acceptor, $\rho$ is the relative position of $\mathrm{H}$ for a particular value of $R$, and $\theta$ is the angle between vectors $\overrightarrow{\mathrm{DA}}$ and $\overrightarrow{\mathrm{DH}}$. The relationship between $\rho$ and the $\mathrm{D}-\mathrm{H}$ distance $r$ is given by the following:

$$
\rho=\left(r-r_{\min }\right) /\left(R-2 r_{\min }\right)
$$

where $r_{\min }=0.8 \AA$ is in principle arbitrary but should be sufficiently small to cover the shortest $\mathrm{D}-\mathrm{A}$ separations. Depending on the position of the transferring $\mathrm{H}$-atom (DH-A or $\mathrm{D}-\mathrm{HA}$ ), bonded interactions on the donor and acceptor side are switched on and off. $V(R, \rho, \theta)$ is parametrized for prototype proton transfer systems such as $\mathrm{H}_{3} \mathrm{~N}-\mathrm{H}^{+} \ldots \mathrm{NH}_{3}$ and $\mathrm{H}_{2} \mathrm{O}-\mathrm{H}^{+} \ldots \mathrm{OH}_{2}$ by fitting it to ab initio data at the MP2/6-311++G(d,p) level and is expressed as follows:

$$
\begin{aligned}
& V(R, \rho, \theta)=D_{\mathrm{eq}}(R)\left[1-\exp \left(-\beta(R)\left(\rho-\rho_{\mathrm{eq}}(R)\right)\right)\right]^{2} \\
& \quad+D_{\mathrm{eq}}(R)\left[1-\exp \left(-\beta(R)\left(1-\rho-\rho_{\mathrm{eq}}(R)\right)\right)\right]^{2} \\
& \quad-D_{\mathrm{eq}}(R)-c+k \theta^{2}
\end{aligned}
$$

where,

$$
\begin{aligned}
& D_{\mathrm{eq}}(R)=p_{1}\left(1-\exp \left(-p_{2} R-p_{3}\right)\right)^{2}+p_{4} \\
& \beta(R)=p_{5}+p_{6} R \\
& \rho_{\mathrm{eq}}(R)=p_{7}\left(\exp \left(-p_{8} R\right)+p_{9}\right) \\
& k=p_{10} \\
& c=p_{11}
\end{aligned}
$$

PES morphing techniques ${ }^{21}$ can be used so that the MMPT potential is capable of describing topologically similar but energetically different hydrogen bonding motifs in an accurate 
and concise way. Shape modification of the PES is necessary to capture effects of the chemical environment (see below). The remaining atoms - aromatic carbon and hydrogen atoms-are described by the standard CHARMM force field. Since both VALBOND and MMPT were developed together with CHARMM22, ${ }^{5,8}$ mixing these force fields is meaningful.

Force Field Parametrization. The reliability and accuracy of a force field depends on its parameters, and parametrization is usually done through careful and sometimes tedious fitting to experimental structure data and/or high level electronic structure calculations. In this work, however, parameters from each force field are directly carried over and already leads to good accuracy as shown in the manuscript. For example, the VALBOND parameters for Platinum, Phosphorus, and Chlorine are taken from Landis' original work $^{5,6}$ and the corresponding Supporting Information.

For the MMPT force field, our previous study of 2-pyridone. 2-hydroxypyridine (2PY2HP) dimer ${ }^{8}$ provides PESs for the $\mathrm{N}-\mathrm{H}-\mathrm{N}$ and $\mathrm{O}-\mathrm{H}-\mathrm{O}$ motifs that can be considered as the zeroth order potentials. One parameter that is related to angular part of MMPT force field has been reparametrized. For isolated 2PY-2HP system, both hydrogen bonding motifs are almost linear, so the angular dependence is not important in our previous study and a heuristic $0.01 \mathrm{kcal} /\left(\mathrm{mol} \cdot\right.$ degre $\left.^{2}\right)$ is used. Here a more carefully parametrized angular potential is needed, so this parameter is refitted and has been determined to be $0.007 \mathrm{kcal} /\left(\mathrm{mol} \cdot\right.$ degree $\left.^{2}\right)$ for $\mathrm{N}-\mathrm{H}-\mathrm{N}$ motif and $0.009 \mathrm{kcal} /\left(\mathrm{mol} \cdot\right.$ degree $\left.^{2}\right)$ for $\mathrm{O}-\mathrm{H}-\mathrm{O}$ motif, respectively. The double hydrogen bonding motif in the $\mathrm{Pt}$ complex is chemically similar to the free $2 \mathrm{PY} 2 \mathrm{HP}$ dimer but is embedded in a rigid framework due to the coordination. The steric and electronic effects of such a constraint can be taken into account by the following PES morphing, ${ }^{21}$

$$
\begin{aligned}
& V^{\mathrm{NHN}}\left(R^{\prime}, \rho^{\prime}, \theta^{\prime}\right)=\lambda_{\mathrm{E}} \cdot V_{0}^{\mathrm{NHN}}\left(R-R_{1}, \rho, \theta\right) \\
& V^{\mathrm{OHO}}\left(R^{\prime}, \rho^{\prime}, \theta^{\prime}\right)=\lambda_{\mathrm{E}} \cdot V_{0}^{\mathrm{OHO}}\left(R-R_{2}, \rho, \theta\right)
\end{aligned}
$$

The morphing variables $\lambda_{\mathrm{E}}=0.8, R_{1}=0.2 \AA$, and $R_{2}=0.08 \AA$ have been chosen to reproduce the $\mathrm{N}-\mathrm{N}$ and $\mathrm{O}-\mathrm{O}$ distances measured by X-ray crystallography. ${ }^{12}$ The resulting MMPT parameters are listed in Table S1 of the Supporting Information, SI.

The CHARMM22 parameter set ${ }^{17}$ is used for all other force field terms required. When CHARMM parameters were missing, those from analogous CHARMM atom types or from relevant literature $^{22,23}$ are taken. To help assign atomic partial charges, natural population analysis (NPA) ${ }^{24}$ has been carried out and MM charges are set to the half of the NPA charges ${ }^{7}$ since NPA generally overestimates partial atomic charges. ${ }^{25}$

Molecular Dynamics Simulations. With rapid evaluation of energies and gradients, molecular dynamics (MD) simulations can be carried out. For MD simulations in the gas phase, the complex was first heated to $300 \mathrm{~K}$ by 6000 steps and equilibrated at that temperature for $100 \mathrm{ps}$. Then a $10 \mathrm{~ns}$ NVE trajectory was generated by free dynamics. The time step was $\Delta t=0.1 \mathrm{fs}$ to follow the rapid proton motion.

MD simulations have also been carried out in explicit solvent including deuterochloroform $\left(\mathrm{CDCl}_{3}\right)$, water $\left(\mathrm{H}_{2} \mathrm{O}\right)$, toluene $\left(\mathrm{C}_{6} \mathrm{H}_{5} \mathrm{CH}_{3}\right)$, dichloromethane $\left(\mathrm{CH}_{2} \mathrm{Cl}_{2}\right)$, deuterodichloromethane $\left(\mathrm{CD}_{2} \mathrm{Cl}_{2}\right)$, and tetrachloromethane $\left(\mathrm{CCl}_{4}\right)$. Topologies and force field parameters are taken from refs 26-28. For these simulations, cubic solvent boxes with suitable sizes were used $\left(\mathrm{CDCl}_{3}:(45.97 \times 45.97 \times 40.86) \AA^{3} ; \mathrm{H}_{2} \mathrm{O}:(34.15 \times 31.04 \times\right.$ 31.04) $\AA^{3}$; toluene: $(50.48 \times 50.48 \times 50.48) \AA^{3} ; \mathrm{CH}_{2} \mathrm{Cl}_{2} \& \mathrm{CD}_{2} \mathrm{Cl}_{2}$ : $\left.(42.64 \times 42.64 \times 37.90) \AA^{3} ; \mathrm{CCl}_{4}:(48.96 \times 48.96 \times 48.96) \AA^{3}\right)$.
The $\left[\mathrm{Cl}_{2} \mathrm{Pt}(6-\mathrm{DPPon})_{2}\right]$ complex was then solvated and the entire system was heated to the desired temperature. Periodic boundary conditions and a cutoff of $12 \AA$ was applied to the shifted electrostatic and switched van der Waals interactions. NVT simulations were carried out using a Nose-Hoover thermostat ${ }^{29,30}$ with a coupling constant of $50 \mathrm{kcal} \cdot \mathrm{mol}^{-1} \cdot \mathrm{ps}^{2}$. Before free dynamics simulations, the system was equilibrated for $100 \mathrm{ps}$.

Electronic Structure Calculations. DFT calculations were carried out using the B3LYP functional ${ }^{31,32}$ with the all-electron 6-31G $(\mathrm{d}, \mathrm{p})$ basis set for $\mathrm{C}, \mathrm{H}, \mathrm{N}, \mathrm{O}, \mathrm{P}$ atoms and a LANL2DZ effective core potential ${ }^{33}$ for $\mathrm{Pt}$ and $\mathrm{Cl}$ atoms. For the NMR and UV-vis spectra, coordinates of the complex were recorded from MD snapshots at regular intervals and used in GaugeIndependent Atomic Orbital (GIAO) ${ }^{34}$ or time dependent DFT (TD-DFT) calculations with a nonequilibrium polarized continuum model (PCM) solvation. To compare computed NMR shielding tensors with experimentally measured proton chemical shifts, the isotropic shielding constants $\sigma_{\text {iso }}(r)$ were referenced to TMS calculated at the same level of theory, i.e., $\delta_{\text {iso }}(r)=\sigma_{\text {ref }}-\sigma_{\text {iso }}(r)$ where $\sigma_{\text {ref }}=31.756 \mathrm{ppm}$. Coordinates, generated every $10 \mathrm{ps}$ from individual $2 \mathrm{~ns} \mathrm{MD}$ trajectories carried out at four different temperatures $(200,250,300$, and 350 $\mathrm{K})$ and in two different solvents $\left(\mathrm{CDCl}_{3}\right.$ and $\left.\mathrm{CD}_{2} \mathrm{Cl}_{2}\right)$, were used in GIAO calculations and then averaged over 200 snapshots. To compute the UV-vis spectrum, snapshots were extracted every 100 ps from a $5 \mathrm{~ns}$ NVE simulation trajectory of $\left[\mathrm{Cl}_{2} \mathrm{Pt}\right.$ (6-DPPon) $\left.)_{2}\right]$ solvated in explicit $\mathrm{CH}_{2} \mathrm{Cl}_{2}$. Transition wavelengths and strength were computed with the CAM-B3LYP functional, ${ }^{35}$ convoluted using Gaussian curves by the cclib package ${ }^{36}$ and averaged over 50 frames. All electronic structure calculations were carried out using Gaussian03 with the grid=ultrafine option. ${ }^{37}$

Infrared Spectrum. Infrared and power spectra are computed from the time correlation functions from $\mathrm{MD}$ simulations. More specifically, the total dipole moment $\vec{M}(t)$ was recorded along the $\mathrm{MD}$ trajectories and correlated over $2^{14}$ time origins to give $C(t)$,

$$
C(t)=\langle\vec{M}(t) \cdot \vec{M}(0)\rangle
$$

To suppress noise, a Blackman filter was used. ${ }^{38}$ Then $C(\omega)$, the Fourier-Transform of $C(t)$, was weighted with the Boltzmann factors to give the infrared spectrum $A(\omega)$,

$$
A(\omega)=\omega\left\{1-\exp \left[-\hbar \omega /\left(k_{\mathrm{B}} T\right)\right]\right\} C(\omega)
$$

where $k_{\mathrm{B}}$ is the Boltzmann constant and $T$ is the temperature. The power spectrum corresponding to internal motions can be computed in a similar way, by replacing the dipole-dipole correlation functions $C(t)$ with position-position correlation functions.

NMR Spectroscopy. All NMR experiments were performed on a Bruker Avance III $600 \mathrm{MHz}$ NMR spectrometer equipped with a self-shielded $z$-axis pulsed field gradient, dual channel broadband inverse probe-head.

Chemical shifts were referenced to residual solvent peaks $\left(\mathrm{CH}_{2} \mathrm{Cl}_{2}, \delta=5.32 \mathrm{ppm}\right)$ and the temperature was calibrated using a Pt100 thermocouple. The NMR sample was prepared by condensing a mixture of $\mathrm{CDCl}_{2} \mathrm{~F}$ and $\mathrm{CDClF}_{2}(0.6 \mathrm{~mL})^{39}$ onto $6 \mathrm{mg}$ of compound $\left[\mathrm{Cl}_{2} \mathrm{Pt}(6-\mathrm{DPPon})_{2}\right]$ in an NMR tube with a Young's tap.

${ }^{1} \mathrm{H}-{ }^{31} \mathrm{P}$ HMBC experiments were performed with 2048 time points in F2 and 32 time increments in the indirect dimension F1, which corresponds to acquisition times of $94.7 \mathrm{~ms}$ (F2) and $1.3 \mathrm{~ms}$ (F1). The delay for the evolution of the long-range 
coupling was set to $62.5 \mathrm{~ms}$. Fourier transformation was performed with 2048 (F2) and 1024 (F1) points.

The ${ }^{31} \mathrm{P}-{ }^{31} \mathrm{P}$ COSY Experiment was performed at $154 \mathrm{~K}$ using permanent ${ }^{1} \mathrm{H}$ decoupling (WALTZ-16). 512 time points in F2 and 256 time increments with 8 scans per increment in the indirect dimension $\mathrm{F} 1$ were recorded, which corresponds to acquisition times of $35.2 \mathrm{~ms}$ (F2), $17.6 \mathrm{~ms}$ (F1), and a total experiment time of $53 \mathrm{~min}$. Fourier transformation was performed with 1024 points in both dimensions and the spectrum was symmetrized.

\section{RESULTS AND DISCUSSION}

Equilibrium Structure. As shown in Table 1 and Figure 1, the calculated equilibrium structure of cis- $\left[\mathrm{Cl}_{2} \mathrm{Pt}(6-\mathrm{DPPon})_{2}\right]$ from the force field (MM structure) compares favorably with structures from X-ray crystallography ${ }^{12}$ (X-ray structure) and DFT optimization (DFT structure). The natural bite angle $(\angle \mathrm{P} 1-\mathrm{M}-\mathrm{P} 2),{ }^{40}$ a popular descriptor for chelating ligands, is reproduced by the $\mathrm{MM}$ structure compared to the X-ray structure (see Table 1). Another useful steric descriptor for

Table 1. Comparison of Selected Bond Lengths and Angles in Equilibrium Structures Determined by X-Ray Crystallography, DFT Optimization and MM Force Field Optimization $^{a}$

$\begin{array}{lccc} & \text { X-ray } & \text { DFT } & \text { MM } \\ \mathrm{Pt}-\mathrm{P} 1(\AA) & 2.256 & 2.313 & 2.312 \\ \mathrm{Pt}-\mathrm{P} 2(\AA) & 2.236 & 2.306 & 2.302 \\ \angle \mathrm{P} 1-\mathrm{Pt}-\mathrm{P} 2\left(^{\circ}\right) & 97.58 & 105.44 & 97.80 \\ \angle \mathrm{Cl}-\mathrm{Pt}-\mathrm{Cl}\left(^{\circ}\right) & 87.17 & 88.18 & 90.80 \\ \mathrm{Pt}-\mathrm{Cl}{ }^{\star}(\AA) & 2.339 & 2.462 & 2.406 \\ \mathrm{~N}-\mathrm{N}(\AA) & 3.070 & 2.966 & 2.967 \\ \mathrm{~N}-\mathrm{H}(\AA) & 0.84 & 1.033 & 1.032 \\ \angle \mathrm{N}-\mathrm{H}-\mathrm{N}\left(^{\circ}\right) & 136.9 & 156.3 & 139.0 \\ \mathrm{O}-\mathrm{O}(\AA) & 2.684 & 2.631 & 2.662 \\ \mathrm{O}-\mathrm{H}(\AA) & 0.86 & 1.003 & 1.001 \\ \angle \mathrm{O}-\mathrm{H}-\mathrm{O}\left(^{\circ}\right) & 164.3 & 173.3 & 178.6 \\ \mathrm{P}-\mathrm{C}^{\star}(\AA) & 1.825 & 1.841 & 1.833 \\ \angle \mathrm{Pt}-\mathrm{P}-\mathrm{C}^{\star}\left(^{\circ}\right) & 114.42 & 114.42 & 110.09 \\ \angle \mathrm{C}-\mathrm{P}-\mathrm{C}^{\star}\left(^{\circ}\right) & 104.67 & 104.15 & 107.21 \\ { }^{\circ} & & & \end{array}$

P-Donor ligands is $\mathrm{S}^{\prime 41}$ constructed from angles at the coordinated phosphines. For these angles, the X-ray and DFT structures give the same values, which differ from those found from the force field calculations by $4^{\circ}$. Further improvement would be possible via the reparametrization of phosphine in VALBOND force field, but will not be pursued in the current work, as the difference is rather small. The $\mathrm{N}-\mathrm{H}$ and $\mathrm{O}-\mathrm{H}$ bond lengths reported in the MM structure are consistent with the DFT structure, and both are larger than those from X-ray experiments. Such a difference can be expected since locating hydrogen atoms in X-ray crystallography is difficult because of their low scattering power and asymmetrical electron density, and the refined structure depends on the computational algorithms used.

Potential Energy Surface. The PES for the hydrogen bonding motif in the cis- $\left[\mathrm{Cl}_{2} \mathrm{Pt}(6-\mathrm{DPPon})_{2}\right]$ complex is further studied in detail. For this, the high-dimensional PES is projected onto a two-dimensional map $V\left(\rho_{1}, \rho_{2}\right)$, following the investigation of similar double proton transfer (DPT) systems such as $2 \mathrm{PY} 2 \mathrm{HP}$ dimer $^{42}$ and formic acid dimer. ${ }^{43}$ The progression coordinate $\rho_{1}:=1 / 2\left(r_{\mathrm{NH}}-1 / 2 r_{\mathrm{NN}}+r_{\mathrm{OH}}-1 / 2 \mathrm{r}_{\mathrm{OO}}\right)$ describes mainly the proton motion and the coordinate $\rho_{2}:=1 / 2\left(r_{\mathrm{NN}}+r_{\mathrm{OO}}\right)$ characterizes the intermonomer vibrations, where $r_{\mathrm{NN}}, r_{\mathrm{OO}}, r_{\mathrm{NH}}$ and $r_{\mathrm{OH}}$ are the separations between $\mathrm{N}-\mathrm{N}, \mathrm{O}-\mathrm{O}, \mathrm{N}-\mathrm{H}$, and $\mathrm{O}-\mathrm{H}$, respectively. All of the remaining degrees of freedom are relaxed. The PES is characterized by two minimum energy configurations corresponding to the two tautomeric forms of $2 \mathrm{PY} 2 \mathrm{HP}$. The first observation from the computed PES is that a second minimum (marked by cross in Figure 2) lies $0.8 \mathrm{kcal} / \mathrm{mol}$ above the global minimum (marked by a plus sign).



Figure 2. Potential energy surface for the hydrogen bonding motif in cis$\left[\mathrm{Cl}_{2} \mathrm{Pt}(6-\mathrm{DPPon})_{2}\right]$. DFT determined minima and transition states are marked with red plus, cross, and dot, respectively. Magenta parallelogram is drawn to cover the points to compare MM and DFT energies, see text for details.

This is also confirmed qualitatively by DFT calculations, which find an energy difference of $0.4 \mathrm{kcal} / \mathrm{mol}$ between these two minima. Although the global minima computed by MM and DFT overlay with each other, the predicted position of this second minimum from MM force field differs from that from DFT method by $\sim 0.1 \AA$ in both $\rho_{1}$ and $\rho_{2}$. Such an asymmetry, which is not observed in prototype systems such as the free $2 \mathrm{PY} 2 \mathrm{HP}$ dimer, is expected since the hydrogen bonding motif is embedded into a complicated chemical environment and can be related to the difference in $\pi$-stacking effects between the aromatic rings in the complex. A transition state for proton transfer is identified via DFT calculations (marked by dot in Figure 2) and lies in the same transition state region observed from the MM computed PES. However, the MM force field predicts a PT energy barrier of $5 \mathrm{kcal} / \mathrm{mol}$, compared to a barrier of $7.9 \mathrm{kcal} / \mathrm{mol}$ found from DFT calculations.

One difficulty of the present force field is the disability to correctly describe ion pair states in which two hydrogen atoms are bonded to the same PY/HPY ring. Compared to DFT calculations, such conformations are overstabilized. DFT calculations find such states at $13 \mathrm{kcal} / \mathrm{mol}$ above the global minimum whereas optimization of such a conformation with the force field leads to a local minimum around $\rho_{1}=0$. However, the stabilization is marginal and does not affect the dynamics simulations because trajectories seldom sample this region of configuration space, as shown in Figure S1 of the SI, which reports projections of configurations onto the $\rho_{1}, \rho_{2}$ PES from 10 ns simulations in the gas phase and $5 \mathrm{~ns}$ in $\mathrm{CDCl}_{3}$.

Further assessment is carried out by comparing a series of single point energy calculations with the $\mathrm{N}-\mathrm{N}$ distance $\mathrm{R}_{\mathrm{NN}}$, the 
$\mathrm{O}-\mathrm{O}$ distance $\mathrm{R}_{\mathrm{OO}}$, the $\mathrm{N}-\mathrm{H}$ bond length $r_{\mathrm{NH}}$, and the $\mathrm{O}-\mathrm{H}$ bond length $r_{\mathrm{OH}}$ fixed and all other degrees of freedom fully relaxed. Such constrained optimizations are carried out with both DFT and MM force field on a regular four-dimensional grid of 108 points. These points are listed in Table S1 of the SI and shown in the magenta parallelogram in Figure 2, and the resulting two sets of energies are compared in Figure 3. The correlation

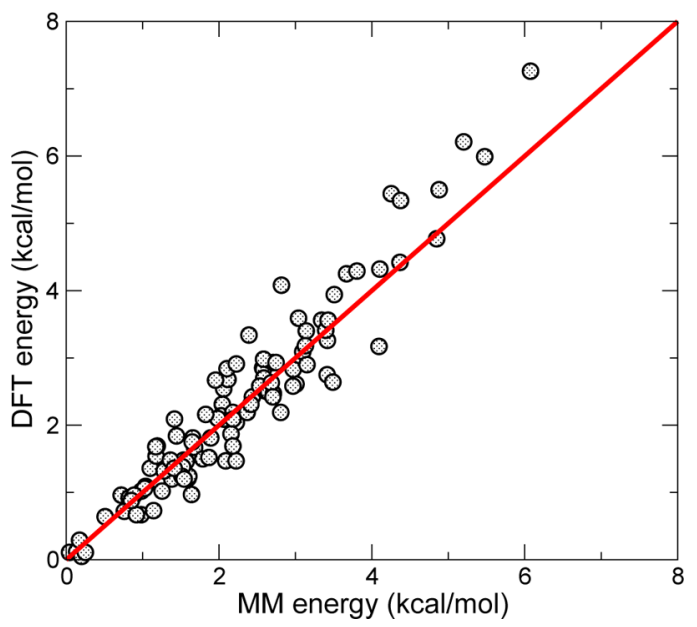

Figure 3. Comparison of MM and DFT energies from structures sampled with MD simulations. The red line indicates a correlation of $r^{2}=1$ and the data have a correlation coefficient of $r^{2}=0.92$.

coefficient $r^{2}$ between the MM and DFT energies is 0.92 , the mean absolute error (MAE) equals $0.31 \mathrm{kcal} / \mathrm{mol}$, and the root mean standard deviation (RMSD) is $0.41 \mathrm{kcal} / \mathrm{mol}$.

IR Spectrum. The experimental infrared spectrum of cis$\left[\mathrm{Cl}_{2} \mathrm{Pt}(6-\mathrm{DPPon})_{2}\right]^{16}$ is characterized by an unusually broad peak between 2500 and $3500 \mathrm{~cm}^{-1}$. DFT calculations on the equilibrium structure did not find any spectral signature in this region. However, by perturbing the equilibrium structure toward the DPT transition state, the harmonic vibrational analysis yielded the characteristic spectral signatures. This suggests that the infrared signatures between 2500 and $3500 \mathrm{~cm}^{-1}$ are dynamical in origin. To better characterize and assign these features, the IR and power spectra for cis- $\left[\mathrm{Cl}_{2} \mathrm{Pt}(6-\mathrm{DPPon})_{2}\right]$ are calculated directly from $\mathrm{MD}$ simulations. One advantage of this approach is that power spectra of individual vibrational motions can be calculated, which helps in assigning spectra. ${ }^{44}$

Computed IR spectra from the $10 \mathrm{~ns}$ MD simulation in gas phase are shown in Figure 4, together with the experimental and DFT calculated ones. Peaks at the red end $\left(1000-1700 \mathrm{~cm}^{-1}\right)$ are consistent with the experimental measurements. The power spectrum of the HPY OH-bending (Figure 4e) and the $\mathrm{CO}$ stretching vibration in both PY and HPY rings (Figure 4f) enable us to assign the measured $1653 \mathrm{~cm}^{-1}$ peak to the CO-symmetric and asymmetric stretching vibration and the $1584 \mathrm{~cm}^{-1}$ peak to $\mathrm{OH}$ rocking vibration. Furthermore, one finds that these two motions are strongly coupled. The power spectrum of the $\mathrm{N}-\mathrm{N}$ distance reports a single peak at $1200 \mathrm{~cm}^{-1}$. The $\mathrm{N}-\mathrm{N}$ separation motions can be regarded as the relative vibration between PY and HPY rings in the complex and correspond to the observed peak at $1240 \mathrm{~cm}^{-1}$, which cannot be assigned with DFT calculations

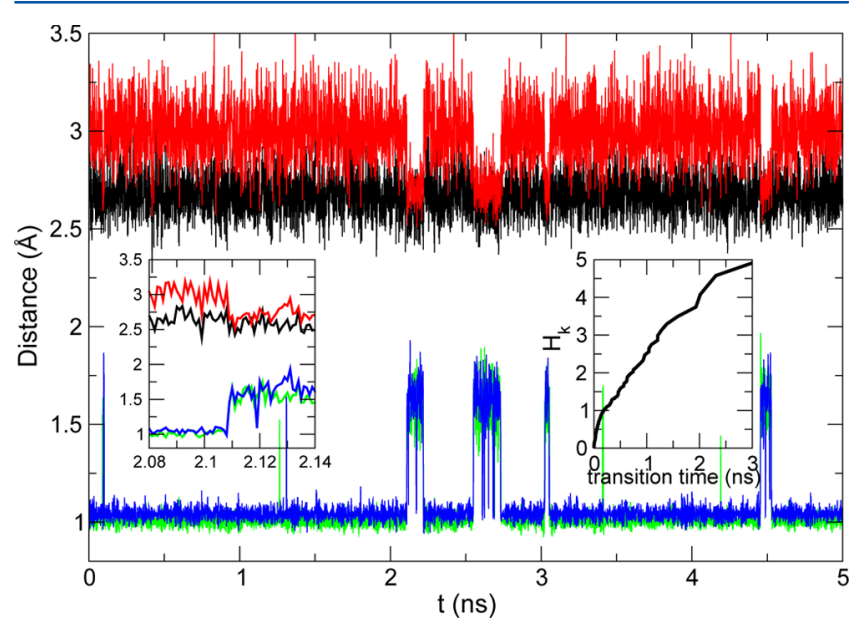

Figure 5. Time series of a $5 \mathrm{~ns}$ molecular dynamics trajectory for cis$\left[\mathrm{Cl}_{2} \mathrm{Pt}(6-\mathrm{DPPon})_{2}\right]$ in $\mathrm{CDCl}_{3}$ solvation at $300 \mathrm{~K}$ showing the $\mathrm{N}-\mathrm{N}$ distances (red), the $\mathrm{O}-\mathrm{O}$ distances (black), the $\mathrm{N}-\mathrm{H}$ distances (blue), and the $\mathrm{O}-\mathrm{H}$ distances (green), respectively. Several double proton transfer events are observed, and the one that occurs at $2.11 \mathrm{~ns}$ is shown in the left inset. DPT reactions are initiated by the shorten of $\mathrm{N} \cdots \mathrm{N}$ distance, and the transfer along $\mathrm{N}-\mathrm{H} \cdots \mathrm{N}$ and $\mathrm{O}-\mathrm{H} \cdots \mathrm{O}$ motifs are concerted. Hazard plot based on a total of 50 ns simulations in explicit solvent is plotted in the right inset, from which a proton transfer rate of $1.7 \mathrm{~ns}^{-1}$ is estimated.
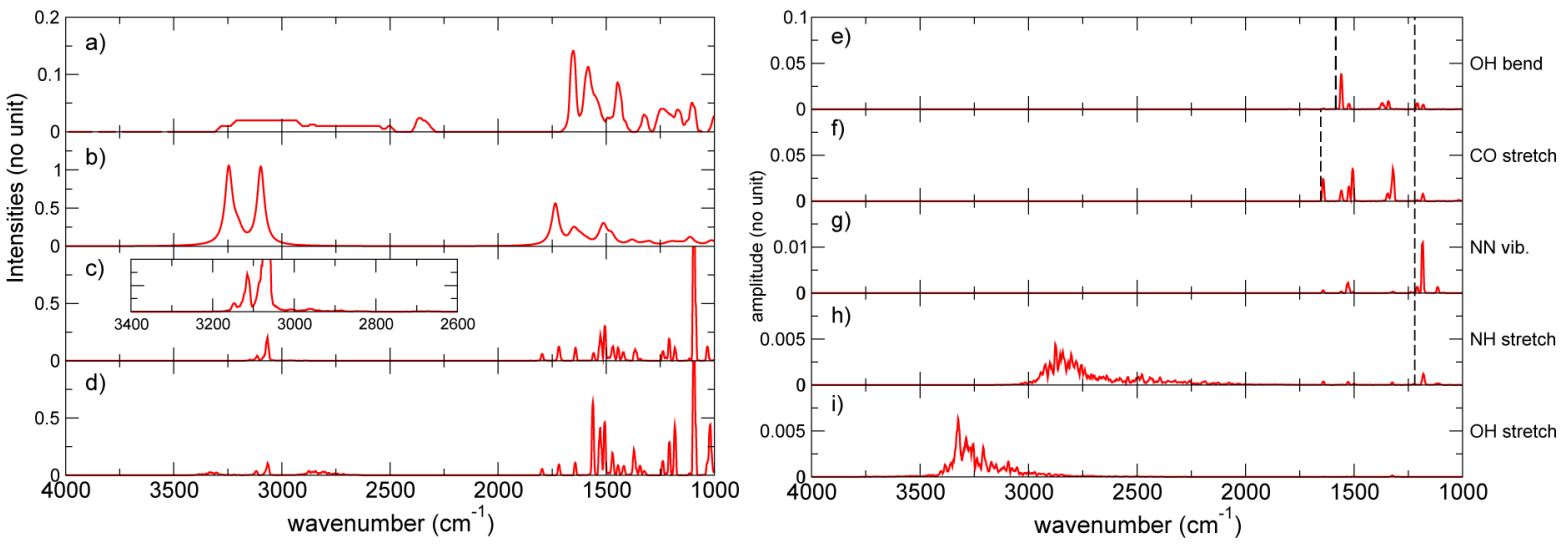

Figure 4. IR spectrum of cis- $\left[\mathrm{Cl}_{2} \mathrm{Pt}(6-\mathrm{DPPon})_{2}\right]$. (a) Experimental measurement; (b) DFT calculation of the equilibrium structure; (c) computation from $10 \mathrm{~ns}$ NVE MD simulations in gas phase, with a zoom-in of 2600 to $3400 \mathrm{~cm}^{-1}$ in the inset; (d) computation from $2 \mathrm{~ns}$ NVE MD simulations of the complex solvated in $\mathrm{CCl}_{4}$. Power spectrum of individual modes computed from $10 \mathrm{~ns}$ NVE MD simulations are also plotted: (e) OH bending; (f) CO stretching; (g) NN vibration; (h) H vibration in the $\mathrm{N}-\mathrm{H} \cdots \mathrm{N}$ motif; (i) $\mathrm{H}$ vibration in the $\mathrm{O}-\mathrm{H} \cdots \mathrm{O}$ motif. The dash lines correspond to 1653 , 1584, and $1240 \mathrm{~cm}^{-1}$, respectively. 
a)
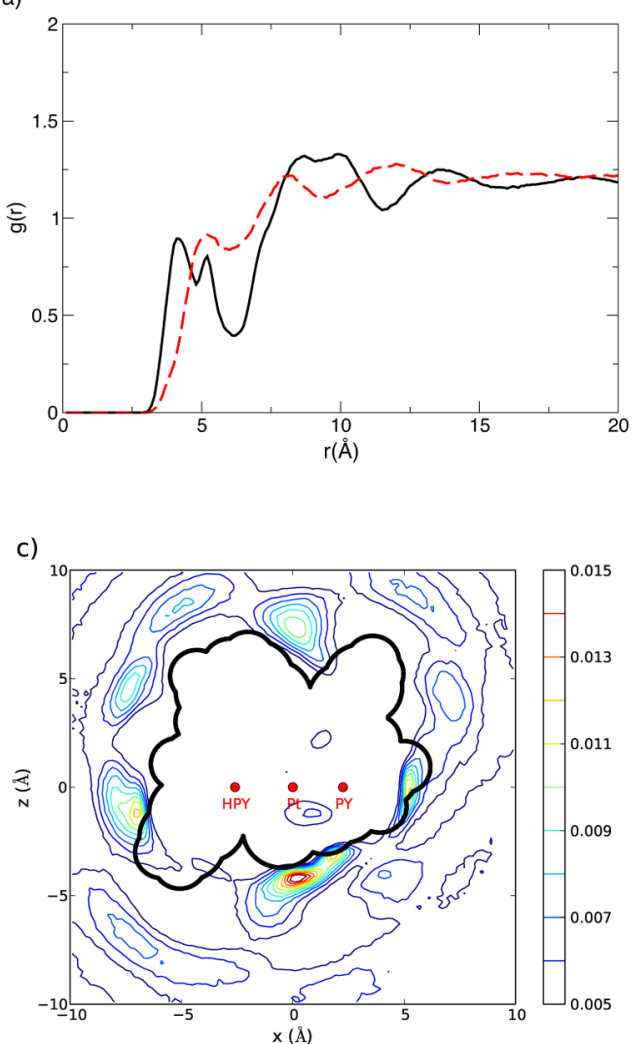

b)

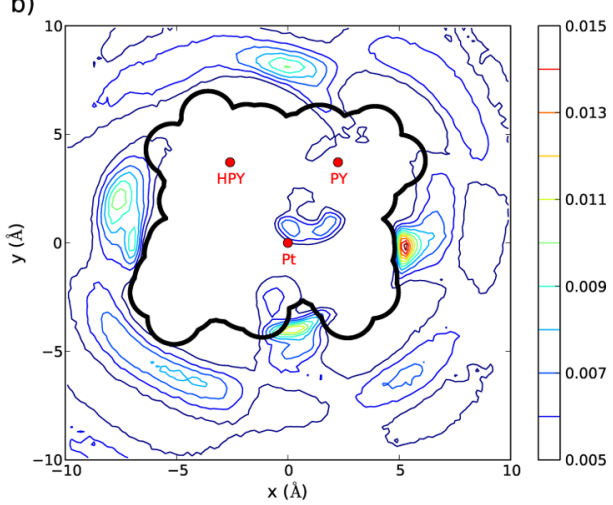

d)

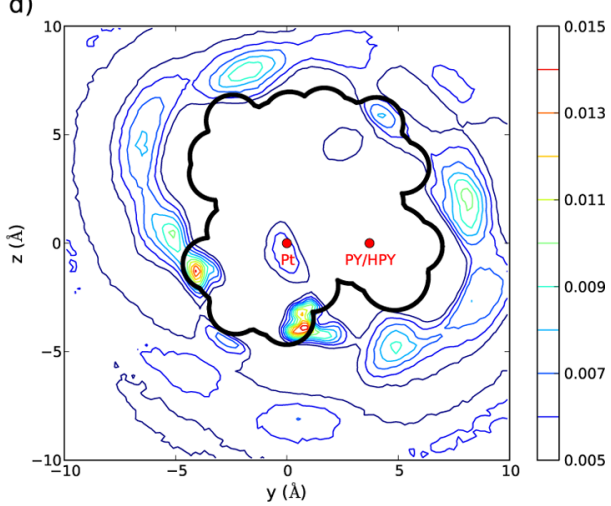

Figure 6. The distribution of solvent molecules $\left(\mathrm{CDCl}_{3}\right)$ around the Pt complex during $50 \mathrm{~ns} \mathrm{MD}$ simulations. (a) the radial distribution function $g(r)$ of $\mathrm{CDCl}_{3}$ molecules as a function of the distance to the Pt atom (black solid line) and the center of mass of the PY and HPY rings (red break line). Panels b, $\mathrm{c}$, and $\mathrm{d}$ show projections of the distribution $g(x, y, z)$ onto the $x-y-, x-z-$, and $y-z-$ planes. The density distribution of $\mathrm{CDCl}_{3}$ molecules is constructed by reorienting the MD trajectory with the Pt atom at $(0,0,0)$ and the center of mass of the PY and HPY rings in the $x-y$ plane. The contours are plotted from 0.005 to 0.015 at the interval of 0.001 . The unit is per solvent molecules per frame. As a comparison, the VdW envelope of the minimized complex (see Figure 1) is also shown as a black solid line.

due to the considerable anharmonicity. It is worthwhile to mention that this peak occurs in the IR spectra of the $\left[\mathrm{Cl}_{2} \mathrm{Pt}\right.$ (6-DPPon $)_{2}$ ] complex but is missing in the spectrum of the 6-DPPon ligand itself. (See Figure 11 in ref 16.)

For the $\mathrm{OH}$ - and $\mathrm{NH}$-stretch, power spectra spread from 3000 to $3500 \mathrm{~cm}^{-1}$ and from 2500 to $3000 \mathrm{~cm}^{-1}$, respectively. Therefore, we assign the very broad peak between 2500 and 3500 $\mathrm{cm}^{-1}$ to the proton motions in the hydrogen bonding motif. The experimental spectrum is recorded in $\mathrm{CCl}_{4}$ with $c=10^{-3} \mathrm{M}^{16}$ Although the solution is dilute, it is not identical to the situation in the gas phase for which the above DFT and force field calculations were carried out. Therefore, the IR spectrum from nanosecond $\mathrm{MD}$ simulations in explicit $\mathrm{CCl}_{4}$ solution (and other organic solutes) was also calculated. Spectra of the complex in $\mathrm{CCl}_{4}$, $\mathrm{CDCl}_{3}$, and $\mathrm{CH}_{2} \mathrm{Cl}_{2}$ share similar features. With the presence of these organic solutes in the simulations, the band between 2700 and $3400 \mathrm{~cm}^{-1}$, which corresponds to the hydrogen bonding in the complex, is now visibly broad (see Figure $4 \mathrm{~d}$ and Figure S2 of the SI).

Proton Transfer Dynamics. The MD simulations at $300 \mathrm{~K}$ in explicit $\mathrm{CDCl}_{3}$ find several PT events on the nanosecond time scale (see Figure 5). The transfer is concerted and typically 1 event per nanosecond is found. For a more quantitative assessment of the proton transfer energetics, extensive (50 ns) MD simulations in explicit solvent were carried out. The nuclear dynamics along the double hydrogen bonding motif can be investigated directly from the $\mathrm{N}-\mathrm{N}, \mathrm{O}-\mathrm{O}, \mathrm{N}-\mathrm{H}$, and $\mathrm{O}-\mathrm{H}$ time-series from the MD simulations. Simulations at $300 \mathrm{~K}$ in explicit $\mathrm{CDCl}_{3}$ find several PT events on the nanosecond time scale (see Figure 5). In all cases, double proton transfer is concerted. 147 proton transfer events are observed during a total simulation time of $50 \mathrm{~ns}$. The transition times $t_{1}, t_{2}, \ldots, t_{n}$ between these events are sorted in ascending order and the expectation value of the cumulative hazards ${ }^{45} H_{k}=\sum_{i=0}^{k-1} 1 /(n-i)$ is calculated from which the proton transfer rate-as the slope of $H_{k}\left(t_{k}\right)$ - of $1.7 / \mathrm{ns}$, see Figure 5. Here, a PT event is defined as the system switches between one minimum state to another where the two minimum states are identified by both the difference of $\mathrm{NH}$ and the difference of $\mathrm{OH}$ are larger than $r_{\mathrm{c}}=0.25 \AA$ (see also Figure 2). Slightly larger or smaller cutoff values $r_{\mathrm{c}}$ (such as $0.2 \AA$ or $0.3 \AA$ ) do not significantly affect the results. The Gibbs free energy is determined as $\Delta G=-R T \ln \left(\rho_{\mathrm{TS}} / \rho_{\min }\right)$ where $\rho_{\mathrm{TS}}$ and $\rho_{\text {min }}$ are the populations at the transition state and at the bottom of the well, respectively. From $50 \mathrm{~ns} \mathrm{MD}$ trajectories in explicit $\mathrm{CDCl}_{3}$ solvent, a free energy barrier of $5.8 \pm 0.2 \mathrm{kcal} / \mathrm{mol}$ for the forward reaction and $4.5 \pm 0.2 \mathrm{kcal} / \mathrm{mol}$ for the backward reaction is estimated by bootstrap analysis with 200 resamples. ${ }^{46}$ The fact that DPT is readily observed in the simulations is consistent with the observation that the spectral features in the infrared (see previous section) also suggest that DPT is operative. It should be emphasized that explicitly determining the free energy of activation for DPT from unbiased simulations is only possible because a suitable force field is available. With alternative methods, including pure $\mathrm{QM}$ or mixed $\mathrm{QM} / \mathrm{MM}$ simulations this would not be possible. 


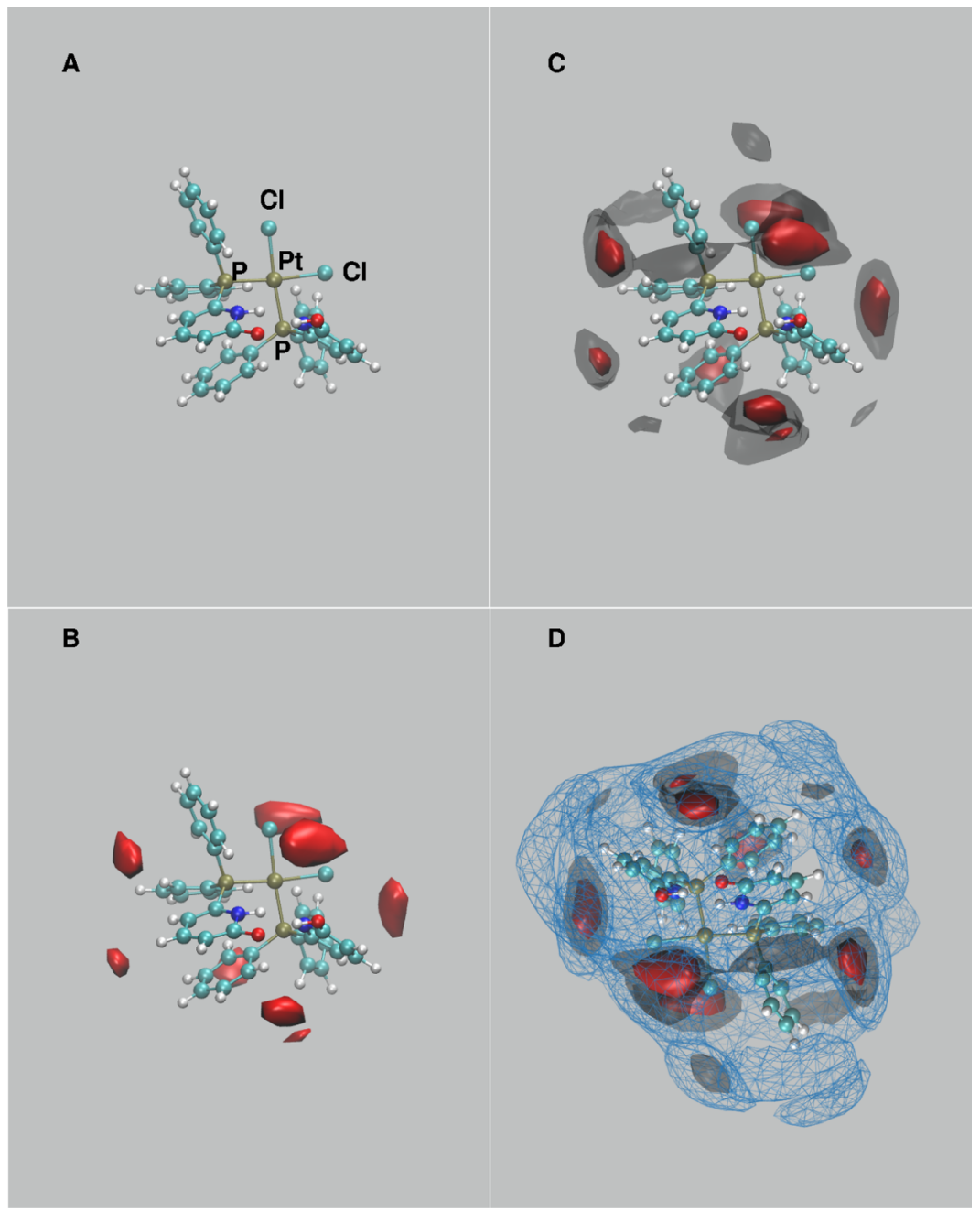

Figure 7. Solvent structure around the catalyst. cis- $\left[\mathrm{Cl}_{2} \mathrm{Pt}(6-\mathrm{DPPon})_{2}\right]$ is shown as ball-and-stick representation (A). Panel B, C, and D show solvent density at isocontours of $60 \%, 50 \%$, and $40 \%$ of the maximum value in red, dark gray, and as a blue mesh. The orientation of the catalyst is identical in all four panels.

Organization of the Solvent. Local solvent organization around the catalyst can be directly inferred from $\mathrm{MD}$ simulations with explicit solvent. A common measure is the solvent radial distribution function $g(r)$, which describes how the density varies as a function of the distance from a particular reference point. Figure 6 shows two distribution functions for different reference points - the Pt atom and the center of mass of the PY/HPY moiety. However, for a spatially demanding solute the simple $g(r)$ is a less informative quantity as it is highly averaged.

Alternatively, the 3D density distribution of the solvent molecules around the Pt complex can be directly visualized as a projection onto different planes. For this, frames along the $50 \mathrm{~ns}$ MD simulations are reoriented so that the Pt atom is at $(0,0,0)$ and the center of mass of the PY and HPY rings lie in the $x-y-$ plane with the same $y$-coordinates. The density is computed as a histogram and then projected onto 2D planes $(x-y-, x-z-$, and $-y-z$-planes), as shown in Figure $6 \mathrm{~b}-\mathrm{d}$. The shape of the complex is also lined out as the van der Waals envelope based on the minimized structure in gas phase by the force field. The 3dimensional representations were built from all solvent molecules within a $20 \times 20 \times 20 \AA$ A block around the catalyst. Space was discretized into $1 \AA^{3}$ voxels and the number of solvent molecules occupying a voxel was counted. The maximum count was renormalized to $\rho(x, y, z)=1$ and all occupation numbers are given in fractions of the maximum occupation. In Figure 7, the solvent density distributions at $40 \%$ to $60 \%$ of the maximum density is reported. The solvent density is inhomogeneous and prominent concentrations are found around the two $\mathrm{Cl}$-atoms which is an unoccupied region in the X-ray structure. Furthermore, the PY/HPY motif appears well solvated whereas $\mathrm{CDCl}_{3}$ clusters less around most of the aromatic rings.

NMR Spectrum. To probe the dynamics on longer time scales, ${ }^{1} \mathrm{H}$ NMR spectra were measured from 298 to $125 \mathrm{~K}$. The results of two-dimensional Heteronuclear Multiple Bond Correlation $(\mathrm{hmbc})$ NMR experiment are shown in Figure 8a. Apart from the expected correlations to the aromatic protons, a cross peak to the signal at $13.0 \mathrm{ppm}$ is clearly visible, whereas no such correlation was obtained for the resonance at $12.5 \mathrm{ppm}$. The observed scalar coupling between ${ }^{1} \mathrm{H}$ and ${ }^{31} \mathrm{P}$ clearly assigns the low field signal $(13.0 \mathrm{ppm})$ to the $\mathrm{N}-\mathrm{H}-\mathrm{N}$ motif. The amine proton is involved in stronger hydrogen bonding than the hydroxyl proton which is somewhat surprising, given that the electronegativity of oxygen is larger than that of nitrogen. However, the results are supported by the observation that DPT is always triggered by transfer along the NHN motif (see Figure 5), and reflect the dynamical nature of DPT in the complex. 


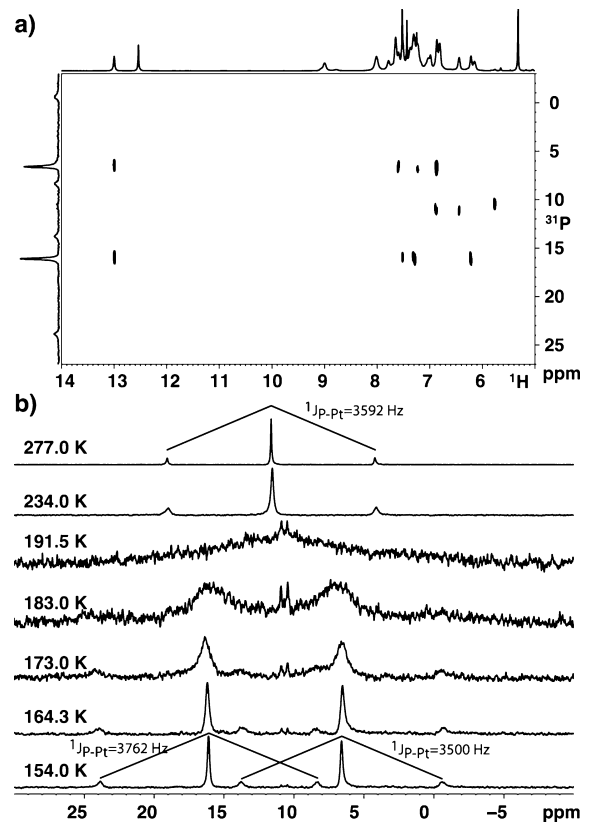

c)

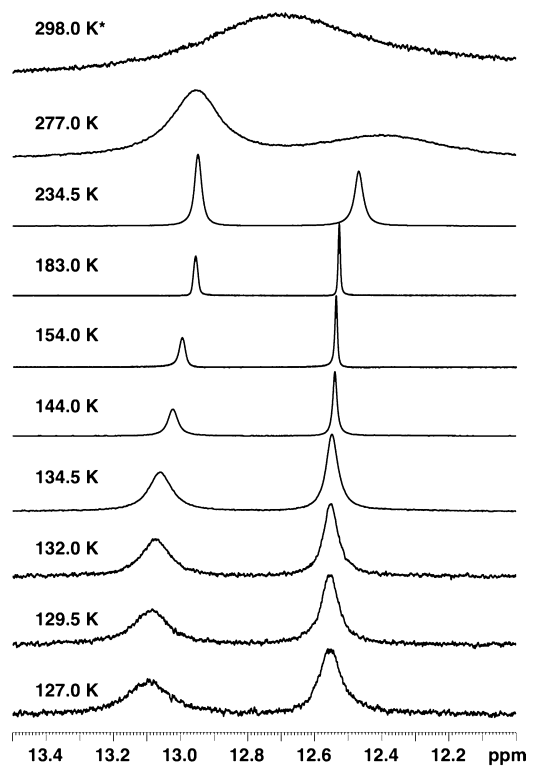

Figure 8. NMR spectrum of cis-[ $\left[\mathrm{Cl}_{2} \mathrm{Pt}(6-\mathrm{DPPon})_{2}\right]$ : (a) $2 \mathrm{D}-{ }^{1} \mathrm{H}-{ }^{31} \mathrm{P}-\mathrm{hmbc}$ NMR spectrum at $160 \mathrm{~K}$; (b) Variable temperature ${ }^{31} \mathrm{P}$ NMR spectrum; (c) Variable temperature ${ }^{1} \mathrm{H}$ NMR spectrum (11.5-14 ppm). The ${ }^{1} \mathrm{H}$ NMR spectra at $298 \mathrm{~K}$ (marked by $\star$ ) was recorded in $\mathrm{CD}_{2} \mathrm{Cl}_{2}$, while the remaining spectra were measured with the complex solvated in $\mathrm{CDCl}_{2} \mathrm{~F}$.

Computationally, NMR characteristics were determined by combining Gauge-independent atomic orbital (GIAO) calculations with $\mathrm{MD}$ ensemble averaging (see SI). Chemical shifts for the protons involved in the DPT motifs are observed at 12.5 and $13.0 \mathrm{ppm}$. It is worth pointing out that the present $\mathrm{MD}$ simulations assign the low field signal $(13.0 \mathrm{ppm})$ to the $\mathrm{N}-\mathrm{H}-$ $\mathrm{N}$ proton and the resonance at $12.5 \mathrm{ppm}$ to the $\mathrm{O}-\mathrm{H}-\mathrm{O}$ proton, which is at variance with calculation on the DFT-optimized structure as well as our assignment in the previous work based on electronegativity. ${ }^{16}$ This result from the present MD simulations has been confirmed by unambiguous detection of a scalar coupling between the $\mathrm{NH}$ proton and a ${ }^{31} \mathrm{P}$ nucleus in the hmbc spectrum (Figure 8a).

In variable temperature ${ }^{1} \mathrm{H}$ NMR experiments, three coalescence phenomena were identified at different temperatures, $T_{\mathrm{c}}^{(1)}=325 \mathrm{~K}$, $T_{\mathrm{c}}^{(2)}=190 \mathrm{~K}$ and $T_{\mathrm{c}}^{(3)} \approx 120 \mathrm{~K}$, respectively. The first coalescence at $T_{\mathrm{c}}^{(1)}$ is related to rotation and tautomerization of the pyridone and hydroxypyridine rings, as already discussed in our previous work. ${ }^{16}$ The second coalescence phenomenon takes place between 277 and $154 \mathrm{~K}$ in the aromatic region. The symmetry observed in the phenyl ring proton spectrum at $277 \mathrm{~K}$ breaks down upon cooling, and at least 17 signals can be identified from the ${ }^{1} \mathrm{H}$ NMR spectrum at 154 $\mathrm{K}$, indicating a $\mathrm{C}_{1}$ species with no overall symmetry (see Figure $\mathrm{S} 6$ of the SI). In accordance with this second coalescence temperature, $T_{\mathrm{c}}^{(2)} \approx 190 \mathrm{~K}$, a similar behavior is observed in the $T$-dependent ${ }^{31} \mathrm{P}$ NMR measurement (Figure $8 b$ ). The sharp resonance for the averaged signal of the two $\mathrm{P}$ atoms at $277 \mathrm{~K}$ broadens on cooling, coalesces at $T_{\mathrm{c}}^{(2)}$ and eventually splits into two sharp lines at $154 \mathrm{~K}$. The two slow exchange signals integrate to $1: 1$ and both display the corresponding Pt satellites from ${ }^{195} \mathrm{Pt}-{ }^{31} \mathrm{P}$ coupling $\left({ }^{1} J_{\mathrm{Pt}-\mathrm{P}_{1}}=3762\right.$ $\mathrm{Hz}$, and ${ }^{1} J_{\mathrm{Pt}-\mathrm{P}_{2}}=3500 \mathrm{~Hz}$ ), indicating both phosphorus are coordinated to the metal in a cis arrangement. There was no apparent coupling between the two ${ }^{31} \mathrm{P}$ resonances as they both appear as singlets (see Figure $8 \mathrm{~b}$ ). However, a ${ }^{31} \mathrm{P}-{ }^{31} \mathrm{P}$ cosy experiment at $154 \mathrm{~K}$ (Figure S7 of the SI) clearly shows weak correlation peaks between the two ${ }^{31} \mathrm{P}$ resonances, establishing that both $\mathrm{P}$ donor atoms are coordinating to the same Pt center and polynuclear species or a mixture of two different complexes is unlikely.

From Eyring's equation, an activation barrier of $7.7 \mathrm{kcal} / \mathrm{mol}$ is deduced. This barrier does not correspond to the double proton transfer process because, interestingly, a ${ }^{31} \mathrm{P}-\mathrm{hmbc}$ spectrum at $154 \mathrm{~K}$ shows correlations of equal intensities between the $\mathrm{NH}$ proton and both of the phosphorus signals (see Figure 8a), which indicates that the $\mathrm{NH}$ proton is still shared by two nitrogen atoms and rules out the possibility of this process being DPT. It should be noted that in the equilibrium structures one of the four phenyl rings in the complex is oriented in a parallel fashion to the pyridone ring (see Figure 1). As mentioned above, such a $\pi-\pi$ interaction breaks the symmetry between the PY and HPY rings, while the DPT motif is kept intact (see Figure 2), and thus provides the two $\mathrm{P}$ atoms with different chemical environments. This suggests that the second coalescence at $T_{\mathrm{c}}^{(2)}$ corresponds to the hindered rotation of phenyl rings along the $\mathrm{P}-\mathrm{C}$ bonds. To explore the possibility of such a process, several 100 ns gas-phase $\mathrm{MD}$ simulations have been carried out at $300 \mathrm{~K}$ and the $\mathrm{Pt}-\mathrm{P}-\mathrm{C}-\mathrm{C}$ dihedral angles of respective rings in the $\mathrm{Pt}$ complex are analyzed. As shown in Figure 9, the hindered rotation along the $\mathrm{P}-\mathrm{C}$ bonds can occur on the submicrosecond time scale, and such a process involves a collective rotation of all six aromatic rings.

When the system is further cooled (the sample solidifies at $125 \mathrm{~K})$, the onset of a next coalescence involving the $\mathrm{NH}$ resonance signal is observed (Figure $8 \mathrm{c}$ ). This indicates that the $\mathrm{NH} \cdots \mathrm{N}$ and $\mathrm{N} \cdots \mathrm{HN}$ states will be in slow exchange below a coalescence temperature $T_{\mathrm{c}}^{(3)}$, and hence assigns the corresponding process to the (double) proton transfer along the $\mathrm{N}-\mathrm{H}-\mathrm{N} /$ $\mathrm{O}-\mathrm{H}-\mathrm{O}$ motif. By assuming a coalescence temperature $T_{\mathrm{c}}^{(3)}$ of 120 to $125 \mathrm{~K}$ and difference in chemical shift for the two signals in (hypothetical) slow exchange between $0.2 \mathrm{ppm}$ and $5 \mathrm{ppm}$, the activation barrier $\Delta G$ of DPT is estimated to be in the range of $4.7-5.7 \mathrm{kcal} / \mathrm{mol}$. This compares favorably with the prediction $(5.8 \mathrm{kcal} / \mathrm{mol})$ from the VALBOND/MMPT force field presented in this work. 


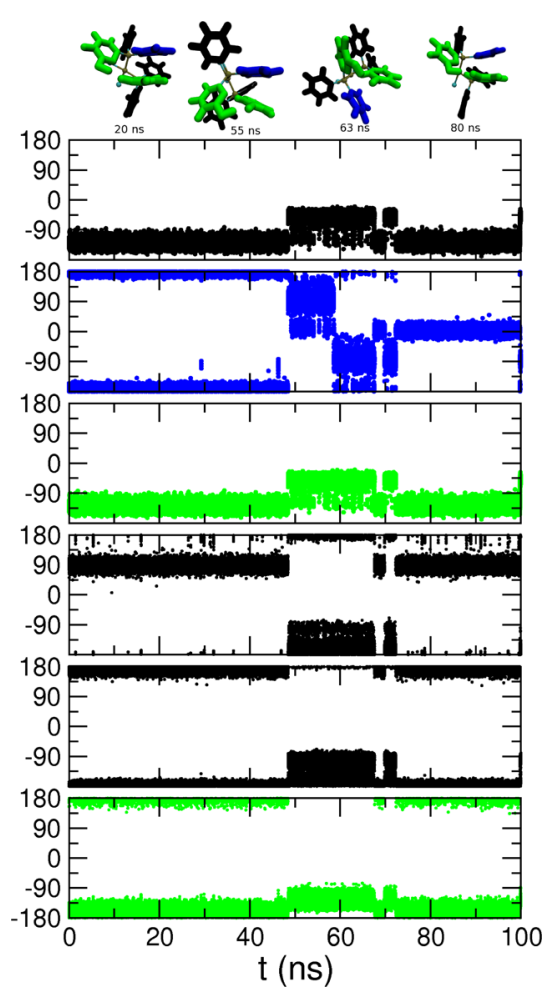

Figure 9. Rotation of the aromatic rings along a $100 \mathrm{~ns} \mathrm{MD}$ simulation of cis- $\left[\mathrm{Cl}_{2} \mathrm{Pt}(6-\mathrm{DPPon})_{2}\right]$ in gas phase at $300 \mathrm{~K}$. The dihedral angles respect to the $\mathrm{Pt}-\mathrm{P}$ bonds as illustrated in the schemes are plotted in black (phenyl rings), green (pyridone and hydroxypyridine rings) and blue (the phenyl rings that is parallel to the pyridone ring). It can be observed that around $48 \mathrm{~ns}$ all six aromatic rings rotates about $90^{\circ}$, and after several nanoseconds the phenyl ring that was previously in a faceto-face arrangement to the pyridone ring flips. At $72 \mathrm{~ns}$, another collective rotation renders rings in their initial orientation except the phenyl ring, which has rotated for $180^{\circ}$.

\section{CONCLUSIONS}

The present work is - to our knowledge-the first in-depth comprehensive study of the nuclear dynamics including solvent effects of a transition-metal catalyst. The major finding of the present study is the important role of intermolecular dynamics in such systems. Of particular relevance is the insight that proton transfer is operative. This is found from combining atomistic simulations with suitable force fields and infrared and NMR spectroscopies as experimental techniques.

In solution, direct "proof" for PT is usually difficult to establish. This contrasts with experiments in the gas phase where proton transfer is generally associated with a tunneling splitting of spectral signatures. ${ }^{47,48}$ In solution, typical effects indicative of proton transfer include the broadening of spectral features, in particular in the infrared. Broad spectral features have previously been observed for isolated 2PY-2HPY in the gas phase. ${ }^{42,49}$ Highresolution spectroscopy has supported that double proton transfer along this motif occurs. ${ }^{50}$ However, previous NMR experiments have provided evidence for PT where in the ${ }^{31} \mathrm{P}$ NMR spectra ${ }^{16}$ only one signal is observed which indicates that the phosphorus bonded to the PY ring and that bonded to the HPY ring are magnetically equivalent, i.e., tautomerization via double proton transfer might take place on NMR time scales. $\mathrm{MD}$ simulations at $300 \mathrm{~K}$ in explicit $\mathrm{CDCl}_{3}$ find several concerted PT events on the nanosecond time scale (Figure 5). The free energy for DPT from VALBOND/MMPT simulation of 5.8 $\mathrm{kcal} / \mathrm{mol}$ compares favorably with estimated activation barriers between 5 and $6 \mathrm{kcal} / \mathrm{mol}$ from NMR experiments.

In summary, by combining atomistic simulations and variabletemperature NMR experiments three distinct elementary processes involving the conformational dynamics in a Pt-based catalyst relevant to homogeneous catalysis could be characterized (Figure 10). The



Figure 10. Processes that correspond to the three coalescence phenomena observed in the variable temperature NMR spectrum. From top to bottom: rotation and tautomerization of the pyridone and hydroxypyridine rings (coalescence temperature $T_{c}^{(1)}=325 \mathrm{~K}$, energy barrier $\Delta G^{(1)}=15.1 \mathrm{kcal} / \mathrm{mol}$ ); hindered rotation of the phenyl rings (coalescence temperature $T_{\mathrm{c}}^{(2)}=190 \mathrm{~K}$, energy barrier $\Delta G^{(2)}=7.7 \mathrm{kcal}$ / $\mathrm{mol}$ ); intramolecular double proton transfer (coalescence temperature $T_{\mathrm{c}}^{(3)} \approx 120 \mathrm{~K}$, energy barrier $\left.\Delta G^{(3)} \approx 5 \mathrm{kcal} / \mathrm{mol}\right)$.

broad features in the IR spectrum around $2500 \mathrm{~cm}^{-1}$, which are correctly captured by the atomistic simulations in explicit solvent, together with the simulations for the DPT-dynamics and the NMR data support that double proton transfer along the $\mathrm{H}$-bonding motifs occurs at low temperatures. The geometry, energetics, and dynamics of a molecular catalyst is decisive for its activity and selectivity in catalysis. Hence, a deep insight into these factors becomes crucial in order to understand the origins of activity and selectivity, with the goal to develop more efficient catalysts in the future.

\section{ASSOCIATED CONTENT}

\section{S Supporting Information}

Additional calculated IR spectra, and calculated and experimentally measured NMR spectra, together with tables and plots concerning the force field parameters and potential energy surface of cis- $\left[\mathrm{Cl}_{2} \mathrm{Pt}(6-\mathrm{DPPon})_{2}\right]$ complex, are provided. This material is available free of charge via the Internet at http://pubs. acs.org/.

\section{AUTHOR INFORMATION}

\section{Corresponding Author}

*E-mail: m.meuwly@unibas.ch.

\section{Notes}

The authors declare no competing financial interest.

\section{ACKNOWLEDGMENTS}

Funding of both groups via the IRTG 1038 "Catalysts and Catalytic Reaction for Organic Synthesis" from DFG and the Swiss National Science Foundation is acknowledged. The work in Basel is further supported by the Swiss National Science Foundation under Grant Nos. 200021-117810, 200020-132406, and the NCCR MUST. The work in Freiburg is supported by the 
Fonds of the Chemical Industry (PhD fellowship to U.G.) and the Alfred-Krupp Award (to B.B.).

\section{REFERENCES}

(1) Houk, K. N.; Cheong, P. H.-Y. Nature 2008, 455, 309-313.

(2) Clemente, F.; Houk, K. Angew. Chem., Int. Ed. 2004, 43, 57665768.

(3) Mitsumori, S.; Zhang, H.; Cheong, P.; Houk, K.; Tanaka, F.; Barbas, C. J. Am. Chem. Soc. 2006, 128, 1040-1041.

(4) Barder, T. E.; Buchwald, S. L. J. Am. Chem. Soc. 2007, 129, 1200312010.

(5) Root, D. M.; Landis, C. R.; Cleveland, T. J. Am. Chem. Soc. 1993, 115, 4201-4209.

(6) Landis, C. R.; Cleveland, T.; Firman, T. K. J. Am. Chem. Soc. 1998,

120, 2641-2649.

(7) Tubert-Brohman, I.; Schmid, M.; Meuwly, M. J. Chem. Theo. Comp. 2009, 5, 530.

(8) Lammers, S.; Lutz, S.; Meuwly, M. J. Comput. Chem. 2008, 29, 1048.

(9) Comba, P.; Kerscher, M. Cord. Chem. Rev. 2009, 253, 564-574.

(10) Miyashita, A.; Yasuda, A.; Takaya, H.; Toriumi, K.; Ito, T.; Souchi, T.; Noyori, R. J. Am. Chem. Soc. 1980, 102, 7932-7934.

(11) Kranenburg, M.; van der Burgt, Y. E. M.; Kamer, P. C. J.; van Leeuwen, P. W. N. M.; Goubitz, K.; Fraanje, J. Organometallics 1995, 14, 3081-3089.

(12) Breit, B.; Seiche, W. J. Am. Chem. Soc. 2003, 125, 6608-6609.

(13) Seiche, W.; Schuschkowski, A.; Breit, B. Adv. Synth. Catal. 2005, $347,1488-1494$.

(14) Chevallier, F.; Breit, B. Angew. Chem. Int. 2006, 45, 1599-1602.

(15) Wieland, J.; Breit, B. Nat. Chem. 2010, 2, 832-837.

(16) Gellrich, U.; Huang, J.; Seiche, W.; Keller, M.; Meuwly, M.; Breit, B. J. Am. Chem. Soc. 2011, 133, 964-975.

(17) MacKerell, J. A. D.; et al. J. Phys. Chem. B 1998, 102, 3586-3616.

(18) Cleveland, T.; Landis, C. G. J. Am. Chem. Soc. 1996, 118, 60206030.

(19) Landis, C. R.; Firman, T. K.; Root, D. M.; Cleveland, T. J. Am. Chem. Soc. 1998, 120, 1842-1854.

(20) Firman, T. K.; Landis, C. R. J. Am. Chem. Soc. 2001, 123, 1172811742 .

(21) Meuwly, M.; Hutson, J. J. Chem. Phys. 1999, 110, 8338-8347.

(22) Sjoqvist, J.; Linares, M.; Norman, P. J. Phys. Chem. A 2010, 114, 4981-4987.

(23) Lienke, A.; Klatt, G.; Robinson, D. J.; Koch, K. R.; Naidoo, K. J. Inorg. Chem. 2001, 40, 2352-2357.

(24) Glendening, E. D.; Reed, A. E.; Carpenter, J. E.; Weinhold, F. NBO Version 3.1.

(25) Guerra, C. F.; Handgraaf, J.-W.; Baerends, E. J.; Bickelhaupt, F. M. J. Comput. Chem. 2004, 25, 189-210.

(26) Vanommeslaeghe, K.; Hatcher, E.; Acharya, C.; Kundu, S.; Zhong, S.; Shim, J.; Darian, E.; Guvench, O.; Lopes, P.; Vorobyov, I.; Mackerell, A. D. J. Comput. Chem. 2009, 31, 671-690.

(27) Fox, T.; Kollman, P. A. J. Phys. Chem. B 1998, 102, 8070-8079.

(28) Kab, G.; Schroder, C.; Schwarzer, D. Phys. Chem. Chem. Phys. 2002, 4, 271-278.

(29) Nose, S. J. Chem. Phys. 1984, 81, 511-519.

(30) Hoover, W. G. Phys. Rev. A 1985, 31, 1695-1697.

(31) Lee, C.; Yang, R.; Parr, W. G. Phys. Rev. B 1988, 37, 785.

(32) Becke, A. D. J. Chem. Phys. 1993, 98, 5648-5652.

(33) Hay, P. J.; Wadt, W. R. J. Chem. Phys. 1985, 82, 270-283.

(34) Wolinski, K.; Hinton, J. F.; Pulay, P. J. Am. Chem. Soc. 1990, 112, $8251-8260$.

(35) Yanai, T.; Tew, D. P.; Handy, N. C. Chem. Phys. Lett. 2004, 393, 51-57.

(36) O’Boyle, N. M.; Tenderholt, A. L.; Langner, K. M. J. Comput. Chem. 2008, 29, 839-845.

(37) Frisch, M. J. et al. Gaussian 03, Revision C.02; Gaussian, Inc.: Wallingford, CT, 2004.

(38) Allen, M. P.; Tildesley, D. J. Computer Simulation of Liquids; Clarendon Press: Oxford, 1987.
(39) Siegel, J.; Anet, F. J. Org. Chem. 1988, 53, 2629-30.

(40) Freixa, Z.; van Leeuwen, P. W. N. M. Dalton Trans. 2003, 18901901.

(41) Dunne, B. J.; Morris, R. B.; Orpen, A. G. J. Chem. Soc., Dalton Trans. 1991, 653-661.

(42) Meuwly, M.; Müller, A.; Leutwyler, S. Phys. Chem. Chem. Phys. 2003, 5, 2663-2672.

(43) Miura, S.; Tuckerman, M. E.; Klein, M. L. J. Chem. Phys. 1998, $109,5290-5299$.

(44) Lammers, S.; Meuwly, M. J. Phys. Chem. A 2007, 111, 1638-1647.

(45) Helfand, E. J. Chem. Phys. 1978, 69, 1010.

(46) Paliwal, H.; Shirts, M. R. J. Chem. Theo. Comp. 2011, 7, 41154134.

(47) Tanaka, K.; Toshimitsu, M.; Harada, K.; Tanaka, T. J. Chem. Phys. 2004, 120, 3604-3618.

(48) Daly, A. M.; Bunker, P. R.; Kukolich, S. G. J. Chem. Phys. 2010, 132, 201101.

(49) Roscioli, J. R.; McCunn, L. R.; Johnson, M. A. Science 2007, 316, 249-254.

(50) Borst, D. R.; Rosciolia, J. R.; Pratt, D. W.; Florio, G. M.; Zwier, T. S.; Mueller, A.; Leutwyler, S. Chem. Phys. 2002, 112, 3717-3726. 